\title{
PARTICIPAÇÃO DAS FAMÍLIAS NA ESCOLA E CONTRIBUIÇÕES DA PSICOLOGIA ESCOLAR NA MEDIAÇÃO DESTA RELAÇÃ $O^{*}$
}

\author{
Patrícia Sabina Marafon** \\ Celso Francisco Tondin***
}

Resumo: O artigo relata pesquisa que teve como tema a participação da família na escola pública e as possíveis contribuições da Psicologia Escolar crítica na mediação da relação família-escola. O referencial teórico-metodológico utilizado foi o da Análise Institucional e o estudo realizou-se por meio da pesquisa-intervenção em uma escola da rede pública estadual localizada em um município da região oeste de Santa Catarina. Evidenciou-se na pesquisa que a maioria das práticas de participação existentes na escola se refere à frequência dos familiares a reuniões, entregas de boletins e confraternizações, bem como, em menor escala, ao Conselho Escolar e na organização das confraternizações. Os familiares dizem que têm passado a procurar a escola por iniciativa própria a fim de acompanharem a vida escolar dos filhos, mas os profissionais consideram que há famílias que não participam a contento. Os contatos entre escola e família são sentidos, especialmente pelos familiares, como de proximidade e de abertura. A Psicologia Escolar crítica pode atuar como mediadora da relação escola-família no sentido de contribuir para a criação de dispositivos de participação que possibilitem o exercício da atividade decisória de todos, superando a ideia de participação como mero sinônimo de frequência e colaborando para a construção de sujeitos democráticos.

Palavras-chave: Participação. Família e escola. Psicologia Escolar.

Abstract:The article reports research that was based on the family's participation in public school and the possible contributions of School Psychology critical in mediating family-school relationship. The theoretical and methodological framework used was the Institutional Analysis and 
the study was carried out through research-intervention in a state public school located in a town west of Santa Catarina. It was proven in research that the majority of existing practices of participation in school refers to the frequency of family meetings, delivery of newsletters and social gatherings, and to a lesser extent, the School Board and the organization of gatherings. Family members say they have to look past the school on its own initiative in order to monitor their children's school life, but professionals say there are families who do not participate satisfactorily. The contacts between school and family are felt, especially by family members, such as proximity and openness. School Psychology can act as a critical mediator of school-family relationship in order to contribute to the creation of devices that enable participation in the exercise of all decision-making activity, exceeding the idea of participation as a mere synonym for frequency, and cooperating to build democratic subjects.

Keywords: Participation. Family and school. School Psychology 


\section{Introdução}

O presente artigo decorre de pesquisa realizada entre os anos 2008 e 2009, que teve como tema a participação da família na escola e as possíveis contribuições da Psicologia Escolar crítica na mediação da relação família-escola. O estudo foi realizado em uma escola da rede pública estadual localizada em um município da região oeste de Santa Catarina.

De acordo com a Proposta Curricular de Santa Catarina (2005), valorizar a participação é dar possibilidades para as pessoas se envolverem nas atividades e permitir que se qualifiquem através das experiências adquiridas neste processo. Assim, não há participação mais ou menos importante, pois o seu intento é o de "[...] transformar a lógica dos valores impostos pelos segmentos que detêm o poder político e econômico, exige aprendizagem e esta só irá acontecer, se todas as contribuições forem valorizadas." (Santa Catarina, 2005, p. 14).

Neste sentido, é importante que se conheça como tem se dado a participação da família no espaço escolar, especialmente quando as políticas públicas de educação têm apregoado a relevância da interação familiares-profissionais para o pleno desenvolvimento do processo ensino-aprendizagem e para a democratização da instituição escolar.

Ao mesmo tempo, torna-se desafio para a Psicologia Escolar pensar na relação família-escola como objeto de intervenção à medida que o psicólogo, orientado por uma perspectiva crítica, pode contribuir como mediador dessa relação, lançando-se à busca de articular experiências e saberes para a construção de espaços de participação e de construção de sujeitos democráticos.

Pensar na escola e em seus processos educativos é pensar de acordo com a compreensão da realidade social na qual esta instituição está inserida, levando em conta a história, a cultura e os valores emergentes da realidade em que a escola e seus atores sociais foram constituídos. Nesse sentido, para Romanelli 
(2005) a educação é vista como mediadora entre o gesto cultural e sua continuidade, ou seja, é na interação dos homens, em sua tradição, valores e cultura, que o sujeito constitui-se, transformase e modifica o meio no qual está inserido.

Analisar a escola como espaço sociocultural significa percebê-la sobre o olhar da cultura, que considera o movimento das práticas cotidianas, levando em conta, mulheres e homens, trabalhadores, adultos e crianças, alunos e professores, jovens e idosos, negros e brancos, sujeitos sociais presentes na história, construtores de sua história. (Dayrell, 1996, p. 136).

Assim, falar da escola como espaço de propagação da cultura requer compreender os sujeitos que nela participam como atores de uma história, de uma cultura e de um modo de vida particular. No entanto, Bock (2003) alerta-nos que a educação é caracterizada como um processo social por meio do qual a sociedade impõe seus modelos e valores, ou ainda, um processo que responde às necessidades de grupos dominantes da sociedade adulta. Neste aspecto, definir a educação como um processo social regido por valores e normas que constituem a sociedade, é pensar também na atuação da família e da escola neste processo educacional, pois, ainda hoje, a família é caracterizada como a primeira instância responsável por impor normas e valores sociais e culturais à criança e a escola por dar continuidade a esse processo, mas principalmente transmitir o conhecimento acadêmico. Este ensino tem enfatizado os resultados da aprendizagem, utilizando-se de propostas e estratégias homogêneas independente muitas vezes da idade, experiências, ritmos e origem social de seus sujeitos.

A prática escolar passa a considerar apenas uma parte da dimensão dos atores que dela participam, desconsiderando sua dimensão humana, sua história e cultura, tornando o 
conhecimento um produto, sendo considerados seus resultados e não as experiências de seu processo, valorizando os conteúdos e as estratégias de ensino, mas não sua diversidade (Dayrell, 1996). Assim, de um lado temos as famílias com suas histórias e modos de vida particulares, inseridos em uma determinada cultura, do outro, temos também os profissionais que atuam na escola, também com suas histórias e modos de vida particulares. Assim, a família transmite ao aluno o conhecimento de acordo com a realidade em que vivem, seus valores e costumes, já a escola tradicional, por sua vez, transmite um saber técnico e objetivo impossibilitando em muitos momentos a reflexão ou a articulação com a realidade em que esses alunos foram se constituindo. Desse modo, pensar na educação como espaço cultural é pensar em um espaço de tradições, histórias, valores, desejos, é pensar nas experiências de vida de cada um, suas relações e trocas cotidianas.

Esta pesquisa teve como objetivos identificar, a partir da visão dos familiares e professores, como se dá a participação dos familiares de alunos das séries iniciais no contexto escolar, e apontar possíveis contribuições do psicólogo para o processo interativo família-escola.

Este texto está estruturado de forma a apresentar os procedimentos metodológicos da pesquisa. A seguir, os resultados são apresentados e discutidos de modo a pensar primeiramente sobre a participação das famílias na escola e, em seguida, a respeito das possíveis contribuições da Psicologia Escolar crítica na mediação da relação escola-família. Finalizase, com reflexões que podem contribuir para o tema em questão.

\section{Procedimentos metodológicos}

A pesquisa teve caráter qualitativo que, de acordo com Creswell (2007), se utiliza de perspectivas reivindicatórias/ 
participatórias. A estratégia de investigação adotada foi a pesquisa-intervenção, com referencial teórico-metodológico da Análise Institucional.

Segundo Rocha (2006), pensar nas pesquisas participativas é problematizar as relações entre o investigador e o que é investigado, entre o sujeito e objeto, teoria e prática, com a perspectiva do estabelecimento de condições para a captação das informações no cotidiano das culturas, grupos e organizações populares. Assim, o conhecimento se constrói entre o saber já elaborado e incorporado nos pressupostos do pesquisador e o fazer como produção contínua que organiza a ação investigativa. Desta forma, o campo da intervenção só se constitui quando se passa à contextualização das experiências cotidianas no prisma da análise sócio-histórico-política, sendo fundamental o processo ativo tanto do pesquisador quanto do pesquisado, buscando a construção de uma atitude investigativa. Rocha e Aguiar (2003, p. 66) apontam que "a pesquisa-intervenção consiste em uma tendência das pesquisas participativas que busca investigar a vida de coletividades na sua diversidade qualitativa assumindo uma intervenção de caráter socioanalítico".

Dessa forma, a pesquisa-intervenção, com base na Análise Institucional, analisa os efeitos das práticas no cotidiano institucional, desconstruindo territórios e facultando a criação de novas práticas. Assim, o papel de pesquisador é o de um intelectual implicado, buscando a constante reflexão de suas práticas no campo a ser pesquisado e as implicações que sua presença neste espaço poderá desenvolver no campo e em si mesmo. O pesquisador, nesta perspectiva, analisa suas implicações e referências institucionais, analisando também o lugar que ocupa no cotidiano de acordo com sua história. Coloca também em análise os efeitos das práticas no cotidiano institucional, desconstruindo territórios e facultando a criação de novas práticas. Enfim, para Barros (2007, p. 231-232), 
[...] a implicação não é uma questão de vontade, de decisão consciente. Ela inclui uma análise do sistema de lugares, o assinalamento do lugar que ocupa, que busca ocupar e do que é designado ocupar com os riscos que isto implica, esta aproximação com o campo, mostra-nos que ambos - pesquisador e pesquisado, ou seja, sujeito e objeto do conhecimento se constituem no mesmo momento, no mesmo processo.

A pesquisa foi realizada em uma escola da rede pública estadual localizada em um município da região oeste de Santa Catarina que atende populações da zona rural e da zona urbana, mas com predominância rural, o que lhe confere contornos culturais específicos e instigantes. A escola oferece do préescolar à $9^{\mathrm{a}}$ série, mas para os fins deste estudo optou-se pelo recorte das séries iniciais, dado o tempo restrito da pesquisa e que as séries iniciais e as demais séries trariam diferenças presentes na relação família-escola que talvez não fosse possível dar conta de conhecer, analisar e problematizar de forma consistente.

A primeira etapa da pesquisa se deu no mês de setembro de 2008, quando foi realizado o levantamento de dados do histórico e do Projeto Político Pedagógico da escola. $\mathrm{Na}$ segunda etapa, entre os meses de setembro e dezembro, foram realizadas observações não-estruturadas de alguns momentos e atividades realizadas na escola. As informações foram registradas em diários de campo, compondo, assim, dados relevantes, sentimentos, percepções e implicações do pesquisador com o campo pesquisado. $\mathrm{Na}$ terceira etapa, foram realizadas entrevistas semiestruturadas com seis profissionais (professores e direção da escola). Na quarta etapa, pretendia-se realizar entrevistas semiestruturadas com 25 familiares, cinco de cada série, da $1^{\mathrm{a}}$ à $5^{\mathrm{a}}$ serie, os quais foram convidados, por meio de bilhete entregue aos alunos, de forma aleatória, para 
comparecerem à escola em data e horário definidos. Por este procedimento compareceu à entrevista apenas uma mãe, o que fez com se buscasse outra estratégia, que foi a visita às casas das famílias durante o mês de janeiro de 2009. Assim foi possível entrevistar, pelo tempo disponível para esta tarefa e pelo fato de que em muitas casas não se encontrava ninguém no momento da visita, 13 familiares, dentre eles 10 mães, duas avós e um pai, o que constitui uma amostra aleatória. Como se pode notar, a grande maioria das entrevistas foi realizada com as mães, por estas estarem em casa no momento das entrevistas e os maridos estarem fora trabalhando.

As famílias residem em duas comunidades moradoras de dois espaços próximos entre si, mas com realidades distintas. Uma das comunidades pertence à zona rural que se localiza a uma distância maior da escola, apresentando condições socioeconômicas correspondentes ao que denominamos geralmente de famílias de classe média. A outra comunidade pertence à zona urbana e é nela que fica a escola, sendo que as famílias residem próximas da instituição e apresentam condições socioeconômicas precárias. Nas visitas, constatou-se que algumas crianças desta comunidade não estudam na escola pesquisada, mas em uma outra localizada em uma cidade vizinha porque, segundo os moradores, é oferecido transporte gratuito e os alunos têm a garantia de vagas para realizar o ensino médio.

A análise das implicações possibilitou considerar que, ao se entrar no campo de pesquisa com estratégias já definidas, o pesquisador pensa ingenuamente que elas serão seguidas rigidamente. Porém, sabe-se que o pesquisador não é um sujeito neutro e suas práticas interferem constantemente no campo, assim como os sujeitos participantes da pesquisa produzem esse mesmo campo, o que pode favorecer a mudança da direção a ser seguida. O pesquisador, por sua vez, também vai transformando seu lugar na pesquisa por meio do exercício da escuta, do diálogo 
e da empatia com os participantes da pesquisa, o que contribui para a atuação prática no espaço em que se deseja intervir.

A pesquisa foi aprovada pelo Comitê de Ética em Pesquisa da Unochapecó e as entrevistas foram gravadas, após assinatura do termo de consentimento livre e esclarecido, tendo sido transcritas entre os meses de janeiro e abril de 2009. Na análise das informações, a fim de garantir o anonimato utiliza-se as identificações profissional e familiar, sendo que esta última justifica-se pelo fato de que a participação da família na escola não refere-se apenas aos pais, mas sim a todos os membros da família ou cuidadores (pais, mães, avós, tios, irmãos etc.).

A seguir, os resultados são apresentados e discutidos de modo a pensar primeiramente sobre a participação das famílias na escola e, em seguida, a respeito das possíveis contribuições da Psicologia Escolar crítica na mediação da relação escolafamília.

\section{Resultados e discussão}

Os resultados da pesquisa trouxeram dados importantes no que se refere à participação das famílias na escola e como os profissionais da Psicologia podem intervir no espaço escolar. Para apresentação e discussão dos resultados, buscar-se-á, no primeiro tópico, explicitar o conceito de participação bem como alguns estudos sobre a relação família-escola, ambos na perspectiva da construção de sujeitos democráticos, ou seja, de produção da cultura democrática participativa no contexto escolar. Já no segundo tópico, resgatar-se-á brevemente o histórico da relação Psicologia e Educação a fim de apontar possibilidades para a mediação pelo psicólogo dos processos interativos entre profissionais e familiares, em uma perspectiva crítica. 


\section{Participação das famílias na escola}

Para se abordar a participação dos familiares no cotidiano escolar é preciso explicitar o conceito de participação com a qual se opera. Segundo Matos e Maia (1995, p. 102-103), a participação da comunidade no trabalho escolar está dividida em três dimensões, que se articulam e que estão relacionadas às práticas democráticas dentro da escola, quais sejam: "[...] a dimensão metodológico-didática, a dimensão da organização da gestão escolar, e a dimensão da relação escola e sociedade - a questão da participação como elemento de construção de cidadania." Portanto, a ideia de trazer os pais para participar da escola deveria significar a possibilidade deles participarem na tomada de decisões sobre os rumos do processo pedagógico, da organização e da gestão na perspectiva da construção de uma sociedade democrática. Afinal,

A ideia de participação pressupõe um sujeito ativo, que age em conjunto com outros sujeitos, organizamse em um grupo, desenvolvem uma ação, assim a participação não descreve apenas a relação abstrata que existe entre uma parte e o todo, mas sugere-se uma relação entre sujeitos que são ou que fazem parte de um todo, e esse todo é construído pela atividade dos sujeitos (partes). (Matos; Maia, 1995, p. 101):

Neste sentido, entendemos que a participação da família junto à escola pode contribuir para o processo de construção da autonomia dos atores envolvidos no processo educativo, que possibilite a formação de sujeitos capazes de fazer escolhas e de constituírem modos participativos de convivência. Portanto, de acordo com Paro (1995, p. 220), é importante desconstruirmos a ideia de que a escola sozinha seja capaz de contribuir para o desenvolvimento do aluno, pois, “[...] a visão de uma escola 
isolada e autossuficiente em sua tarefa educativa parece incompatível com a natureza mesma de um processo educacional que vise à autonomia do educando em sua atividade de aprender criticamente o mundo natural, humano e social".

No presente estudo, constatou-se como se dá a participação dos familiares de alunos das séries iniciais na escola pesquisada. Ela se dá, segundo familiares e professores, principalmente e na maioria das vezes quando os pais são convocados para participarem de reuniões, entrega de boletins e confraternizações. As falas a seguir corroboram esta afirmação: "Sempre participo, quando tem reunião" (familiar); "Olha, a família participa pouco, só se a gente mesmo chama, solicita, diretamente com a escola" (profissional).

Nestas falas pode-se perceber um certo descompasso: enquanto o familiar afirma que participa "sempre", o profissional considera que há pouca participação, entretanto, ambos concordam que a participação se dá predominantemente quando a escola solicita a presença dos familiares.

A opinião do profissional parece desconsiderar e até desvalorizar as iniciativas aparentemente espontâneas dos familiares de frequentarem a escola, pois, a maior parte dos familiares entrevistados dizem que estão buscando participar da escola não apenas quando convidados, mas também nos momentos em que sentem necessidade, como podemos exemplificar na seguinte fala: "A gente vê a necessidade de conversar alguma coisa, de saber como tá a criança, se tá indo bem [...]. Eu procuro sempre saber" (familiar). Observa-se, assim, que os familiares estão buscando a escola também por iniciativa própria, mesmo que ainda o foco seja o acompanhamento da vida escolar dos filhos por meio de conversas com a coordenação pedagógicas e com os professores.

Pode-se questionar se este esteja sendo um processo de autonomização das famílias ou simplesmente mera reprodução 
da relação predominante, com o diferencial de que aqui não é a escola que convida, mas os familiares que se autorizam a procurar os profissionais? Ou ainda, seria esta uma iniciativa própria das famílias que pode vir a ser embrião de outras formas de participação?

Outro modo de participação das famílias na escola está no auxílio nas tarefas escolares que os filhos devem fazer em casa. Esta forma de participar da escola modifica a prática de estar efetivamente no ambiente escolar, trazendo a participação para um momento extraclasse, no qual os pais e outros familiares podem contribuir talvez mais frequente e processualmente. No entanto, Paro (2007, p. 49) aponta que:

De qualquer forma, é preciso considerar que o preparo e o oferecimento de materiais e de um bom lugar para estudar e fazer as lições é também uma questão de valorização do estudo e de informações que o pai e a mãe tenham a esse respeito. Por isso, é importante que a escola atente para a situação, preocupando-se com as maneiras de fazer chegar até os pais essas informações e toda a orientação necessária a respeito.

Assim, há a necessidade da criação de dispositivos que incentivem e valorizem o trabalho dos pais, buscando um espaço para que os professores possam contribuir com eles e para que estes possam melhor auxiliar os filhos nas tarefas escolares que devem ser realizadas em casa. De tal modo que não se detenha apenas ao conteúdo, mas seja um incentivo que valorize as potencialidades do aluno e o gosto pelo saber.

Outras formas de participação é o trabalho dos familiares junto ao Conselho Escolar e na organização das confraternizações da escola, que envolvem um número bem menor de pais e são menos frequentes que as formas anteriormente citadas.

Tondin (2001) aponta que pensar na escola pública como um 
espaço de participação é ir além dos espaços já estabelecidos, é ir além dos conselhos de classe, reuniões de pais e entregas de boletins. Desenvolver autonomia na escola é buscar novas estratégias de participação, independentemente dos modelos já existentes na comunidade escolar, é ir além das práticas reproduzidas até então, é estar aberto ao diálogo, para que se possa criar um ambiente em que as famílias possam dar suas sugestões e opiniões sobre as práticas que gostariam que fossem realizadas na escola, que beneficiem, numa perspectiva coletivista, todos os membros da comunidade escolar.

De acordo com Paro (2007), muitas escolas têm consciência a respeito da importância da conjugação dos esforços dos pais para o desempenho dos estudantes, porém se reconhece apenas no discurso, não tendo o poder suficiente de levar os pais a agirem neste espaço. Por isso, o trabalho da escola deveria ser o de estimular estes pais a participarem no cotidiano escolar, criando ações de participação, que não se resumissem apenas ao discurso produzido nos conselhos de classe ou nos encontros individuais, mas que atuassem como potencializadores de práticas educativas em benefício da escola, suas famílias e alunos.

A respeito de quem da família participa destes momentos promovidos pela escola, os relatos apontam que mais frequentemente são as mães e eventualmente avós, tios ou irmãos de mais idade, porém, é perceptível o aumento da frequência de pais.

As mães podem participar das atividades escolares quando contam com a ajuda de outros familiares na vida doméstica, sejam eles o marido, avós, tios ou filhos. Por outro lado, quando a frequência maior é dos pais, a explicação é que eles participam mais do que as mães porque elas trabalham em casa, além de terem que cuidar dos filhos porque não contam com a ajuda de ninguém: "Pouco que eu venho participar, porque eu 
tenho menininha pequena, daí eu não participo muito, é meu esposo que participa [...]. Ele mais que vem. Eu venho quando ele tem folga e pode ficar em casa cuidando da menina [...]" (familiar). Verifica-se, assim, que as mães podem participar na escola quando contam com a ajuda de outros familiares na vida doméstica.

Percebe-se também, que os papéis relacionados aos gêneros, que diferenciam o homem e a mulher perante a sociedade, é um dos aspectos que podem ser levados em consideração quando falamos da relação família-escola. Pensando na realidade na qual a escola está inserida, o papel do homem ainda é atribuído como o responsável pelo trabalho e pelo sustento da família, sendo assim considerado como o mais independente. Já a mulher é vista como responsável pelas atividades domésticas e pelo cuidado dos filhos. Isso fica evidente pelas entrevistas, pois, a maior parte delas foram respondidas pelas mães, que estavam, no momento das entrevistas, em casa enquanto seus maridos estavam trabalhando fora.

A realidade de maior participação dos pais também pode ser compreendida devido à grande distância que algumas famílias moram da escola, o que acarreta que nem sempre as mães possam participar, pois necessitam de transporte para se locomover e como não há transporte coletivo e elas não possuem habilitação para dirigir, o marido é quem participa mais, pois possui habilitação e, segundo algumas mães, tem maior "independência" para se deslocar até a escola.

Goode (1970, p. 114) aponta que "[...] o status de esposos e de pais são fixados dentro da família e da sociedade, atribuindo certas atividades aos homens fora da unidade doméstica e a divisão do trabalho dentro da família”. Assim, homens e mulheres desempenham diferentes papéis dentro do sistema familiar, o que com o passar das gerações vão se modificando, pois a frequência de pais na escola é algo mais recente, pois, 
em geral, são mães as que mais participam dos compromissos escolares. Atualmente, em algumas famílias, homens e mulheres dividem as tarefas de casa e sua ida à escola, e o papel do homem, que antes era o de responsável apenas pelo sustento da família, passa também a ser o de auxiliar na educação dos filhos. E a mulher, que até então era responsável apenas pelo cuidado dos filhos e da casa, passa a participar de atividades fora da vida doméstica, como em um trabalho que contribua para o sustento da família, buscando, assim, ajuda de outros membros da família para auxiliar no cuidado dos filhos. Diante disso, os pais e mães passam a deixar os filhos com os avós ou outros cuidadores para poderem trabalhar.

Para que se processe a participação das famílias na escola é importante compreender como é a relação dos familiares, professores e alunos. Um dos familiares entrevistados afirma: "Pelo que eu vi aqui, acho que são todos amigos, porque os professores são bem queridos, conversam bastante com a gente, não são de dizer, 'ah sou professor, só dou aula lá para as crianças e depois deu' [...]." Essa fala denota que o entrevistado percebe que, nas interações entre os familiares e os professores, estes não se colocam em uma relação de superioridade, mas sim numa relação de proximidade com as famílias, o que se apresenta como uma potencialidade para o trabalho conjunto, pois, se pretende-se promover a participação das famílias na escola é necessário a desconstrução do lugar de "expert” ocupado historicamente pelo professor, como autoridade pedagógica e representante da verdade científica, e proporcionar um espaço de troca de saberes entre as famílias, a comunidade e a escola, que depende também dos familiares se autorizarem, como dito por outro entrevistado: "Por mim é tranquilo, depende do interesse que a gente tem, [...], falar com a diretora, a professora, a gente tem que ter uma certa afinidade de articular tudo isso junto, uma interação" (familiar). 
Do ponto de vista dos profissionais, as famílias estão participando da vida escolar, mas isso não é regra geral, como exemplificado na fala: "Têm famílias que levam a sério o filho na escola, que acompanham, vêm ver o que acontece com a filha, com o filho; têm outras que não tão nem aí, a escola que se vire". Essa afirmação demonstra que parcela das famílias estão participando na escola, contribuindo, assim, para uma maior interação entre familiares professores que resulta no acompanhamento do desenvolvimento dos alunos e filhos, mas que outra parcela, segundo os profissionais entrevistados, "não participa" e que disso resulta que "a escola tem assumido a responsabilidade pelo aluno".

A educação é uma prática social compartilhada por diversas instituições e atores, o que, de alguma forma, aponta para a necessidade de que a família e a escola estabeleçam vínculos possibilitadores da plena humanização das novas gerações. Porém, no mesmo sentido encontrado na presente pesquisa, alguns estudos têm apontado que, muitas vezes, escola e família encontram-se em situações de conflito, pois há uma acusação mútua de que as responsabilidades não são cumpridas e sim delegadas, queixa mais comum dos professores em relação aos pais dos alunos (Paro, 1995, 2007; Tondin, 2001). Paro (2007), porém, aponta um aspecto importante sobre a participação dos pais na escola. Para ele, a família e a escola devem se responsabilizar juntos pela educação das crianças, ou seja, precisam conceber a educação como uma corresponsabilidade, o que muda a lógica da fragmentação das responsabilidades para o compartilhamento delas.

Neste sentido, rever o papel da família e da escola dentro da sociedade atual é questionar o que a escola espera das famílias e o que as famílias esperam da escola. Tondin (2001) aponta que, muitas vezes, a escola deve continuar a educação dada pela família e a família, por sua vez, deva continuar a educação dada pela escola. 
A Proposta Curricular de Santa Catarina (2005) aponta para a construção de uma educação democrática que deva possibilitar ao aluno e seus responsáveis, um espaço para participação como cidadãos ativos em todos os âmbitos da sociedade, contribuindo para a construção do senso crítico, opinante, à medida que os pais passem a exercer seu poder na tomada de decisões no âmbito escolar.

Assim, para que ocorra de fato o processo de democratização, a família precisa sentir-se participante da escola, realizando atividades que estimulem e envolvam os atores educacionais na gestão escolar. Por isso, deve-se buscar que a comunidade como um todo esteja envolvida, expressando livremente suas opiniões e participando das deliberações, pois a "participação pressupõe um sujeito ativo, que age em conjunto com outros sujeitos" (Matos; Maia, 1995, p. 101). Desse modo, para se avançar na construção de práticas participativas na escola precisa-se que levar em conta não a participação da comunidade na escola, mas também da escola na comunidade e que este debate apareça associado às tentativas de democratização da sociedade, envolvendo diferentes dimensões dessas práticas, onde pais, professores, alunos e comunidade possam trabalhar juntos em prol de ações que fortaleçam uma rede de relações participativas. É a partir dessa perspectiva que a Psicologia Escolar crítica se propõe a atuar.

\section{Psicologia e Educação}

A Psicologia e a Educação mantém relação histórica. Conhecer como se deu este processo em nosso país, o que farse-á recorrendo a Antunes (2003) e Yazzle (1997), permite compreender como a Psicologia pode atuar na mediação da relação escola-família.

A relação entre Psicologia e Educação é existente desde o período colonial, no qual a Psicologia ainda não era uma 
ciência autônoma, sendo a produção da época considerada como "ideias psicológicas" (Antunes, 2003). Nesta época, o processo educativo das crianças era fonte de ideias psicológicas articuladas ao trabalho educativo, presentes em obras, especialmente de jesuítas.

Já no século XIX, o ensino superior, ora instalado no país, foi uma fonte importante de formulação de ideias psicológicas. Destacam-se teses produzidas por ocasião da conclusão do curso de Medicina que tratavam de questões educacionais, contemplando discussão relativas ao fenômeno psicológico e prescrevendo cuidados para serem seguidos pelas escolas.

Também, a partir da década de 1830, começam a ser instaladas as Escolas Normais, que desde o início, mesmo que de forma ainda pouco sistemática, discutiam a criança e seu desenvolvimento e aprendizagem como base para o estudo da metodologia de ensino. Porém, é somente na segunda metade do século XIX que se explicita mais a preocupação com a relação entre as práticas pedagógicas e o psiquismo infantil. Assim, no fim deste século, passou-se a estudar de modo mais efetivo temas e conteúdos que viriam a caracterizar mais tarde a denominada Psicologia da Educação.

Entre 1890-1930, a Psicologia conquista sua autonomia científica, constituindo-se como área específica de estudo. Neste período, a sociedade brasileira vinha passando por profundas transformações e, com a Proclamação da República, buscava-se uma nova nação, o que demandava a formação de um homem novo, um novo modelo produtivo e novas relações de trabalho, ideias que alimentaram a Escola Nova.

Com as reformas estaduais de ensino na década de 1920 foram criados laboratórios de Psicologia que fundamentavam os princípios da Escola Nova, envolvendo estudos sobre o desenvolvimento infantil, aprendizagem, relacionamento entre professores e alunos, testes pedagógicos e psicológicos. 
Também por volta dos primeiros anos do século XX, surge outro marco de influência para a Psicologia e para a Educação, o movimento da Higiene Mental ${ }^{1}$, que:

[...] via a escola e outras instituições de atendimento à infância como espaços para se prevenir desajustes e conduzir a comportamentos adaptados socialmente, em uma perspectiva clínica, diagnóstica e individualizada [...], aperfeiçoado a partir das técnicas psicanalíticas e dos conceitos de psicopatologia introduzidos pela psiquiatria. (Yazlle, 1997, p. 23).

Por volta de 1930-1962 a Psicologia consolida-se como "[...] área de saber no campo de atuação no Brasil, gerando condições para sua legalização como profissão e para o estabelecimento de cursos regulares para a formação de seus profissionais" (Antunes, 2003, p. 157). Desta forma, a partir da criação da Lei $\mathrm{n}^{\circ} 4119$, de 27 de agosto de 1962, a profissão de psicólogo passa a ser reconhecida legalmente. A partir da década de 1970, por conta de uma atuação dada a partir do modelo clínico e da psicometria, a Psicologia na Educação passa a ser criticada, mais especificamente pelo modo como os testes eram utilizados, como base para o diagnóstico do aluno "problema", e pelo tratamento prescrito, individual e marcado por uma concepção adaptacionista.

Porém, muitos psicólogos buscaram “quebrar” este modelo instituído e inserir na ação pedagógica a troca de saberes com outros profissionais, buscando assim a transformação da realidade educacional. Assim, o psicólogo escolar e os demais profissionais da Educação passaram a agir na direção de

[...] criar possibilidades de construção de uma educação mais democrática e efetiva, sobretudo para as camadas populares, considerando a inevitável 
articulação com a realidade social como um todo e fundamentalmente com o estabelecimento de um compromisso social com ela. (Antunes, 2003, p. 166).

A partir da década de 1980, com base nas ideias formuladas por Patto (1984), os psicólogos deram início a discussões que evidenciaram as transformações necessárias a Psicologia Escolar, buscando pressupostos críticos no que se refere às concepções de homem e às relações entre escola e sociedade (Meira, 2003). Temos aí consolidada a perspectiva crítica em Psicologia Escolar que denunciou o compromisso da ciência psicológica com o projeto capitalista de sociedade.

A mesma autora refere que, primeiramente, houve a necessidade de se romper com o modelo clínico que, por meio do diagnóstico de patologias, detinha-se em culpabilizar o aluno: "[...] os problemas de aprendizagem eram explicados de modo organicista, características individuais de personalidade, comportamentos inadequados, carência social e cultural e desagregação da família" (Meira, 2003, p. 22). Assim, todas essas expressões levam a uma visão tradicional de diagnóstico clínico do psicólogo escolar, em que os problemas eram diretamente relacionados aos alunos.

O rompimento com este modelo leva a um novo direcionamento do trabalho do psicólogo escolar, saindo de uma intervenção que busca uma causa para o problema em direção à criação de novos olhares em torno da Educação, a fim de contribuir para que a escola realmente passe a assumir sua função social. Assim, o psicólogo não é tido mais como um solucionador de problemas, por meio de teorias e práticas psicológicas, mas um profissional que dentro de seus limites auxilia a escola a lidar com as dificuldades cotidianas e no processo de reapropriação de sujeitos críticos e humanizados (Tanamachi; Meira, 2003). 
Essas autoras afirmam que Psicologia que pretenda contribuir com a construção de práticas educativas cidadãs precisa

[...] construir metodologias de trabalho fundadas em um movimento de ação/reflexão/ação, de tal forma que todos os envolvidos possam refletir sobre a própria prática social [...] e comprometer-se com o desenvolvimento de projetos que traduzam em ações concretas essa nova compreensão crítica sobre si mesmo e sobre a realidade social. (Tanamachi; Meira, 2003, p. 53).

Rompe-se, assim, com a ideia do psicólogo escolar tecnicista para colocá-lo na posição de mediador,

[...] que junto a educadores, alunos, funcionários, direção, família e comunidade, poderão avaliar criticamente os conteúdos, métodos de ensino e as escolhas didáticas que a escola faz como um todo. Assim, ele pode participar de um esforço coletivo voltado para a construção de uma compreensão crítica do psiquismo, do desenvolvimento humano e de suas articulações com a aprendizagem e as relações sociais. (Tanamachi; Meira, 2003, p. 53).

Deste modo, essa mediação só será possível se houver projetos concretos no campo da Educação, que articulem processos de participação e de integração das comunidades, famílias, profissionais e alunos, como sujeitos ativos. Tal concepção de trabalho do psicólogo escolar é coerente com a necessária democratização das relações escolares, fator já amplamente compreendido pelos educadores populares como importante para a melhoria da qualidade social da educação.

Assim, a atuação do psicólogo na escola deve estar pautada na bagagem teórico-crítica que vem sendo construída no 
decorrer de suas práticas, considerando a realidade sociopolítica do Brasil e do espaço em que está inserido. Por isso, reproduzir o discurso da pouca participação da família na escola e de que nada ou pouco se pode fazer para a democratização escolar contribui apenas para a naturalização de um fenômeno cultural que tem suas raízes na relação do Estado (neste caso, escola) com a sociedade (famílias), amplamente caracterizada pelo autoritarismo, elitismo, clientelismo e patrimonialismo. Desse modo, direcionar a culpa à família ou à escola é uma estratégia despotencializadora e é por isso que nesta pesquisa buscouse trazer para a discussão alguns aspectos que possam gerar inquietações e instiguem a construção de alternativas que visem à construção da escola como espaço cultural de formação de sujeitos democráticos.

\section{Considerações finais}

Evidenciou-se na pesquisa que a maioria das práticas de participação existentes na escola se refere à frequência dos familiares a reuniões, entregas de boletins e confraternizações, bem como, em menor escala, ao Conselho Escolar e na organização das confraternizações. Alguns familiares relatam acompanhar as atividades encaminhadas pela escola para os filhos fazerem em casa. Os familiares dizem que têm passado a procurar a escola por iniciativa própria a fim de acompanharem a vida escolar dos filhos, mas os profissionais consideram que há famílias que não participam a contento.

As mães entrevistadas podem participar das atividades escolares quando alguém da própria família as substitui no serviço doméstico e no cuidado dos filhos e relatam que os pais são mais "independentes" para esta participação porque não acumulam o trabalho doméstico e porque possuem habitação para dirigir automóvel, nos casos em que as famílias moram 
distantes da escola. Os contatos entre escola e família são sentidos, especialmente pelos familiares, como de proximidade e de abertura.

Percebe-se a necessidade de se trabalhar o olhar de alguns professores sobre estas práticas, para que não se detenham em apenas "criticar" os familiares que, segundo eles, pouco participam da escola, mas que voltem seu olhar na valorização e na manutenção constante de práticas que aproximem ainda mais a família da escola. Porém, com base nos postulados de Matos e Maia (1995), as formas de participação encontradas na escola pouco contribuem efetivamente para a construção de sujeitos ativos e participativos porque não possuem caráter de participação em decisões sobre o processo pedagógico, a organização e a gestão escolar, mas se reduzem à frequência dos familiares nas atividades escolares, por um prisma mais de passividade.

Essa reflexão não pretende ser no sentido de desvalorizar o que tem sido feito, mas problematizar que sujeitos vão se constituindo nestes processos de interação entre profissionais e familiares e apontar que é possível que novas formas de participação sejam implementadas, a fim de que se desnaturalize que estas são as únicas formas de participação das famílias e que, mesmo sendo poucas e até tímidas, não têm sido bem utilizadas por elas. Nota-se, inclusive, que a queixa da não participação das famílias na escola justifica um certo desânimo para que se estabeleçam novos dispositivos de participação e isso talvez seja o mais danoso para a construção da democracia, a descrença nas instituições públicas.

Cabe assim, promover uma nova cultura dentro da escola, lançando-se ao desafio de romper com estereótipos, com verdades instituídas, pouco ou nunca questionadas. Uma cultura em que família-escola não sejam vistas como instâncias separadas, mas sim como espaços que se articulam e se complementam 
nas práticas educativas, criando-se novas estratégias para a participação das famílias na escola, não reproduzindo o discurso da escola, em "só chamar as famílias", mas sim, que a escola também busque ir até estas famílias para conhecer a realidade social em que estão inseridas, contribuindo, assim, para a real efetivação de práticas democráticas e participativas, em prol da valorização destes sujeitos, sua cultura e modos de estar na escola.

Constatou-se também na escola pesquisada, o desejo dos profissionais de contarem com um profissional da Psicologia atuando na escola, não voltado apenas a pesquisas, mas que a escola se tornasse um espaço de estágio para a Psicologia Escolar ou até mesmo para a atuação de um profissional de Psicologia em tempo integral. Porém, muitos professores ainda veem o psicólogo como um "detector" de problemas, papel ocupado historicamente por este profissional a partir do modelo clínico. Em muitos momentos, denota-se que os profissionais não concebem o trabalho da Psicologia Escolar voltado para a escola como um todo, envolvendo as relações entre os profissionais, familiares, alunos e o sistema escolar, mas dirigido apenas às famílias que não participam das atividades escolares ou para o aluno com problemas de aprendizagem.

A Psicologia Escolar crítica pode atuar como mediadora da relação escola-família no sentido de contribuir para a criação de dispositivos de participação que possibilitem o exercício da atividade decisória de todos, superando a ideia de participação como mero sinônimo de frequência e colaborando para a construção de sujeitos democráticos.

A Proposta Curricular de Santa Catarina (2005, p. 13) defende que "[...] precisamos mobilizar a todos, causar abalos nas velhas estruturas, possibilitar aos indivíduos a participação com toda sua integridade, seus sentimentos, ideias e experiências, passando de pessoas passivas a cidadãos ativos". Questionamos: 
há condições para tal? De nada ou pouco adianta termos uma proposta de participação se as condições em que vivem profissionais e familiares não permitem minimamente que eles possam atuar no sentido proposto pela política pública.

Também é necessário mexer nas concepções de educação dominantes. Paro (1995, p. 220) aponta que, na sociedade capitalista, a educação tem sido considerada por muitos como uma mercadoria e que, sendo assim, a relação entre família e educação passa a ser de consumidor/mercadoria, tal como o é na esfera da produção material. Assim, "[...] a família passa a encarar a educação escolar como um produto pronto a ser adquirido no mercado". Nestas condições - da educação vista como uma mercadoria - é fácil depreender que ela possa acontecer distante da família, ocorrendo não como um direito social ao qual se tem acesso, mas numa relação mercadológica, como se a escola oferecesse um "produto" e as famílias o "comprassem", omitindo a importância da escola e da família juntas contribuírem para as trocas de experiências e vivências dentro do ambiente escolar. A escola não é favor, nem mercadoria, por isso as relações não devem ser nem clientelistas e assistencialistas e nem de consumo. A educação é direito e, sendo assim, exige sujeitos que se relacionem de modo democrático e participativo na perspectiva da produção de uma nova cultura escolar e educacional.

Para superar essa situação, Paro sugere, entre outras possibilidades, a criação de grupos de formação que reúnam os pais ou responsáveis pelos alunos mensalmente para discutir temas ligados à educação (televisão, drogas, sexualidade, entre outros), evitando se deter apenas nos problemas da escola. Nestes encontros, os pais participam ativamente, perguntando, manifestando suas opiniões, mostrando-se pertencentes ao grupo. Resulta, assim, atividades satisfatórias tanto para os pais quanto para os professores, e a escola e a família passam 
a dialogar de uma maneira mais clara e objetiva, despertando ainda mais o interesse dos pais pela escola, e o estímulo dos professores, criando espaços de autonomia, participação e aprendizado em torno da cultura e da vida desses sujeitos.

Portanto, a escola deveria investir no fortalecimento de estratégias que permitam aos familiares acompanharem as atividades escolares, beneficiando tanto a escola quanto os familiares dessas crianças, implementando ações que assegurem a parceria entre esses dois ambientes, visando à busca de objetivos em comum e de soluções para os desafios enfrentados pela comunidade escolar.

Por fim, espera-se que a pesquisa possa contribuir para futuros estudos, bem como, para todos aqueles que buscam encontrar possibilidades de trabalho com a temática levantada, provocando novas inquietações nos meios acadêmico e escolar.

\section{Notas}

*Artigo decorrente de Trabalho de Conclusão de Curso de Psicologia da Universidade Comunitária da Região de Chapecó (Unochapecó), vinculado ao Grupo de Pesquisa Práticas Psicológicas e com financiamento do Fundo de Amparo à Pesquisa (ATCC/FAPE) desta universidade.

${ }^{* *}$ Psicóloga graduada pela Universidade Comunitária da Região de Chapecó (Unochapecó). Endereço: Av. Fernando Machado, n. 448-D - Centro Chapecó (SC) - CEP: 89.802-112. Endereço eletrônico: patricia.cco@ unochapeco.edu.br

${ }^{* * *}$ Psicólogo graduado pela Universidade do Vale do Rio dos Sinos (Unisinos), Mestre em Psicologia pela Universidade Federal de Minas Gerais (UFMG), Doutorando em Psicologia pela Pontifícia Universidade Católica do Rio Grande do Sul (PUCRS) e Professor do Curso de Psicologia da Universidade Comunitária da Região de Chapecó (Unochapecó). Endereço: Rua Uruguai, n. 333-E - Centro - Chapecó (SC) - CEP: 89.801-570. Endereço eletrônico: tondin@unochapeco.edu.br. 
1"De outro modo podemos dizer que o movimento higienista pode ser entendido como um movimento 'promovido' pelo Estado para tentar controlar os fluxos e os movimentos migratórios das populações das cidades, com o objetivo de impedir a 'mistura' das classes. Para isso, colocam-se ao seu serviço as áreas médica, jurídica e pedagógica. Num momento em que ocorre a vitória do liberalismo econômico e o Estado se coloca como regulador da produção e dos meios desta produção cabe a ele reger as relações sociais e garantir a reprodução e a manutenção da força de trabalho. A população, em especial os trabalhadores e a população carente, torna-se objeto de investigação e vigilância. A saúde, tanto quanto a educação, passa a ser uma questão fundamental do Estado, no entender da intelectualidade brasileira." (Bastos, 1998, p. 84-85).

\section{Referências Bibliográficas}

ANTUNES, Mitsuko Aparecida Makino. Psicologia e Educação no Brasil: um olhar histórico-crítico. In: MEIRA, Marisa Eugênio Melillo; ANTUNES, Mitsuko Aparecida Makino (Org.). Psicologia Escolar: teorias críticas. São Paulo: Casa do Psicólogo, 2003.

BARROS, Regina Benevides. Grupo: a afirmação de um simulacro. Porto Alegre: Sulina/UFRGS, 2007.

BASTOS, Cristina Pinto da Silva. Uma história recente sobre "o modode-ser-indivíduo": pensando a psicologia no curso de formação de professores do IERJ.1998. 296 f. Dissertação (Mestrado em Educação) Faculdade de Educação, Universidade Federal Fluminense, Niterói, 1996.

BOCK, Ana Mercês Bahia. Psicologia da Educação: Cumplicidade Ideológica. In: MEIRA, Marisa E. M.; ANTUNES, Mitsuko, A. M. (Org.). Psicologia Escolar: teorias críticas. São Paulo: Casa do Psicólogo, 2003. 
CRESWELL, John W. Projeto de pesquisa: métodos qualitativo, quantitativo e misto. 2. ed. Porto Alegre: Artmed, 2007.

DAYRELL, Juarez. A escola como espaço sócio-cultural. In: DAYRELL, Juarez (Org.). Múltiplos olhares sobre a Educação e cultura. Belo Horizonte: UFMG, 1996.

GOOD, William J. A família. Tradução: Antônio A. A. Neto. São Paulo: Livraria Pioneira, 1970.

MATOS, Kelma Socorro Lopes de; MAIA, Maurício Holanda. Escola e comunidade: tomando partido pela participação. Educação em Debate, Fortaleza, ano 17/18, n. 29-32, p. 100-08, 1995.

MEIRA, Marisa Eugênio Melillo. Construindo uma concepção crítica de Psicologia Escolar: contribuições da Pedagogia historicocrítica e da Psicologia sociohistórica. In: MEIRA, Marisa Eugênio Melillo; ANTUNES, Mitsuko Aparecida Makino (Org.). Psicologia Escolar: teorias críticas. São Paulo: Casa do Psicólogo, 2003.

PARO, Vitor Henrique. Por dentro da escola pública. 1. ed. São Paulo: Xamã, 1995.

. Qualidade do ensino: a contribuição dos pais. 3. ed. São Paulo: Xamã, 2007.

PATTO, Maria Helena Souza. Psicologia e ideologia: uma introdução crítica à Psicologia Escolar. São Paulo: T.A. Queiroz, 1984.

ROCHA, Marisa Lopes da; AGUIAR, Katia Faria de. Pesquisaintervenção e a produção de novas análises. Psicologia, Ciência e Profissão, Brasília, v. 23, n. 4, p. 64-73, dez. 2003. Disponível em: $<\mathrm{http}$ //pepsic.bvsalud.org/pdf/pcp/v23n4/v23n4a10.pdf $>$. Acesso em: 29 out. 2011. 
ROCHA, Marisa Lopes. Psicologia e as práticas institucionais: a pesquisa-intervenção em movimento. Psico, Porto Alegre, v. 37, n. 2, p. 169-174, maio/ago. 2006.

ROMANELLI, Geraldo. Autoridade e poder na família. In: CARVALHO, Maria do Carmo Brant de. (Org.). A família contemporânea em debate. 6. ed. São Paulo: Educ, 2005.

SANTA CATARINA, Secretaria de Estado da Educação de. Ciência e Tecnologia. Proposta Curricular de Santa Catarina: Estudos Temáticos. Florianópolis: IOESC, 2005.

TANAMACHI, Elenita Rício; MEIRA, Marisa Eugênio Melillo. A atuação do psicólogo como expressão do pensamento crítico em Psicologia e Educação. In: MEIRA, Marisa Eugênio Melillo; ANTUNES, Mitsuko Aparecida Makino (Org.). Psicologia escolar: práticas críticas. Casa do Psicólogo: São Paulo, 2003.

TONDIN, Celso Francisco. Relação família-escola: uma análise dos processos psicossociais. 2001. 147 f. Dissertação (Mestrado em Psicologia) - Faculdade de Filosofia e Ciências Humanas, Universidade Federal de Minas Gerais, Belo Horizonte, 2001.

YAZLLE, Elisabeth Gelly. Atuação do psicólogo escolar: alguns dados históricos. In: CUNHA, Beatriz Belluzo Brando et al. (Org.). Psicologia na escola: um pouco de história e algumas histórias. São Paulo: Arte e Ciência, 1997. 